\title{
Dielectric Behavior of Ceramic (BST)/Epoxy Thick Films
}

\author{
N. Hadik, A. Outzourhit, A. Elmansouri, A. Abouelaoualim, A. Oueriagli, and E. L. Ameziane \\ Laboratoire de Physique du Solide et des Couches Minces (LPSCM), F.S.S, Université Cadi Ayyad, Marrakech BP 2390, Morocco \\ Correspondence should be addressed to N. Hadik, n.hadik@ucam.ac.ma
}

Received 14 April 2009; Accepted 4 July 2009

Recommended by Yalin Lu

Composite materials were made by mixing powders of $\mathrm{Ba}_{1-x} \mathrm{Sr}_{x} \mathrm{TiO}_{3}(x=0.2$ and 0.4$)$ ceramics and epoxy resin with various volume fractions (vol\%). Dielectric measurements of these composites were performed as a function of filler ratio in the range $100-360^{\circ} \mathrm{K}$ at $10 \mathrm{KHz}$. The dielectric constant of the composite increased with increasing volume fraction varies slightly with temperature. The 20 vol\% of BST(0.4)-epoxy composite had the highest dielectric constant of 19.4 and dielectric loss tangent of 0.027. Among the dielectric mixing models presented, the model of Lichtenecker shows the best fit to the experimental data for both composites.

Copyright (C) 2009 N. Hadik et al. This is an open access article distributed under the Creative Commons Attribution License, which permits unrestricted use, distribution, and reproduction in any medium, provided the original work is properly cited.

\section{Introduction}

Recently, there has been a great interest in a new generation of composite materials exhibiting high dielectric performance with lower cost, size, weight, and easy processability [1-3]. Low dielectric losses and moderate dielectric constants are required for use in microelectronic packaging and principally for decoupling multichip modules (MCMs) [4, 5].

Different elements have been mixed to polymers like carbon, iron, nickel, or conducting polymer [6-9] to tune their electrical properties. On the other hand, ferroelectric ceramic-polymer composite materials are principally used for high density energy storage and for capacitor applications [10-13]. Their properties can be easily adjusted by changing the volume fraction of the ferroelectric material while the matrix integrity was maintained during manufacturing. The grain size of the ceramic powders, the uniformity, the thickness, the interfacial effects, and the porosity of the composites influence the physical properties and the quality of the ferroelectric ceramic/polymer composites [10-13].

Previous studies on ceramics-epoxy composites revealed dielectric constants in the range of 24 and 44 for $\mathrm{BaTiO}_{3}$ and PMN thick films for 40 vol\% [14]. A lower value of 23 was noted for $\mathrm{Nb}_{2} \mathrm{O}_{5}$ doped $\mathrm{TiO}_{2}$ ceramics-epoxy films prepared by screen printing [15]. Other authors obtained dielectric constants as high as 75 in the case of $\mathrm{CaCu}_{3} \mathrm{Ti}_{4} \mathrm{O}_{12}$ (CCTO) ceramic-epoxy mixtures for a concentration reaching $64 \%$ [16].

Different laws have been proposed to fit the experimental dielectric constants for two component mixtures, and to predict the effect of each phase on the dielectric properties [17]. Models such as the series, parallel, Hashing-Shtrikman, and Lichtenecker models were developed under various assumptions concerning arrangement of inclusions and their shape [18].

In this work, ceramic-epoxy composites were fabricated using $\mathrm{Ba}_{1-x} \mathrm{Sr}_{x} \mathrm{TiO}_{3}(x=0.2$ and 0.4$)$ powders mixed with Bisphenol A epoxy. The dielectric proprieties of composites with ceramic loadings of 5, 10, 15, and $20 \mathrm{vol} \%$ were studied as a function of temperature.

\section{Materials and Methods}

The powders of BST ceramics were prepared from high purity barium carbonate $\left(\mathrm{BaCO}_{3}\right)$ (Fluka 98.5\%), strontium carbonate $\left(\mathrm{SrTiO}_{3}\right)$ (Riedel-de Haen 96\%), and titanium dioxide $\left(\mathrm{TiO}_{2}\right)$ (Arcos $98 \%$ ) precursors. The starting powders corresponding to $\mathrm{Ba}_{0.8} \mathrm{Sr}_{0.2} \mathrm{TiO}_{3}$ (BST(0.2)) and $\mathrm{Ba}_{0.6} \mathrm{Sr}_{0.4} \mathrm{TiO}_{3}$ (BST(0.4)) were calcined at $1200^{\circ} \mathrm{C}$ in air for 1 hour and a half. The obtained powders were ground in an agate Mortar and pestle and then mixed with a solution of epoxy (Bispfenol-A-Diglycidylether) and its hardener (Triethylenetetramine) at different volume fractions of $0,5,10$, 


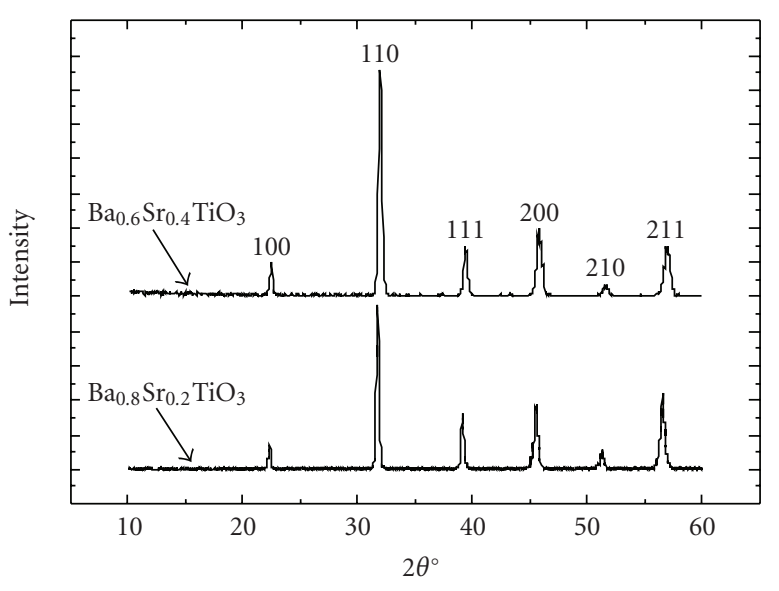

Figure 1: X-ray diffraction pattern of $\operatorname{BST}(0.2)$ and $\operatorname{BST}(0.4)$ ceramics powders.

15 , and $20 \mathrm{vol} \%$, which were calculated using the weight and density of calcined BST and epoxy. The density of BST $(0.2)$ and $\operatorname{BST}(0.4)$ powders is 5.797 and 5.703, respectively, as determined from the measured lattice parameters, while that of the epoxy and its hardener is 1.151 and 1.025, respectively, as given by the manufacturer (Struers). The mixture was blended for 20 minutes and thick film samples, with a thickness of about $100 \mu \mathrm{m}$, were cast on ITO/glass substrate by the knife-edge method. Films with volume fractions exceeding $20 \%$ were not made as homogeneous mixtures were difficult to make and the obtained thick films have a poor quality.

For dielectric measurements, an aluminium electrode was deposed on the samples by vacuum thermal evaporation. The dielectric measurements were performed from 100 to $360^{\circ} \mathrm{K}$ using a Keithley LCZ 3330 meter in the frequency range of $40 \mathrm{~Hz}$ to $100 \mathrm{kHz}$.

The Microstructures of samples were examined by scanning electron microscopy (SEM) using JEOL JSM 5500 SEM equipped an EDAX Falcon EDS analyser. On the other hand, X-ray diffraction analysis was performed using the Philips X'pert diffractometer.

\section{Results and Discussion}

Figure 1 shows the X-ray diffraction patterns of BST ( $x=0.2$ and $x=0.4)$ powders at room temperature. The results reveal that the ceramics have a single perovskite-type phase after calcination at $1200^{\circ} \mathrm{C}$. No peaks corresponding to secondary phases or unreacted precursors were observed. The lattice parameters of the two compositions are, respectively, $0.3974 \mathrm{~nm}$ and $0.3960 \mathrm{~nm}$. The SEM micrographs of BST $(x=0.2$ and $x=0.4)$ ceramics powders, shown in Figures 2 (a) and 2(b), reveal a distribution of grain size being in the range of $0.5-2 \mu \mathrm{m}$, with an average size of $1 \mu \mathrm{m}$.

Figures 2(c) and 2(d) depict the microstructure of the BST-epoxy composite thick films with $10 \%$ and $15 \%$ volume fractions, respectively. A uniform dispersion of ceramic fillers in the epoxy matrix is obtained as revealed by the SEM micrographs. In addition, no pores were observed in these thick films.

\section{Dielectric Measurements}

The dielectric properties of sintered ceramics at $1400^{\circ} \mathrm{C}$ for 75 minutes measured at $10 \mathrm{KHz}$ are shown in Figure 3. The Curie temperature which corresponds to the ferroelectric to paraelectric transition is 353 and $280 \mathrm{~K}$, respectively, for $\operatorname{BST}(0.2)$ and BST(0.4), respectively. The loss tangent did not exceed 0.065 and 0.024 and the maximum dielectric constants at $10 \mathrm{KHz}$ are 1665,1880 , respectively, for the two compositions.

Figure 4 shows the dielectric constant of pure epoxy, BST(0.2)-epoxy and BST(0.4)-epoxy composites thick films, with ceramics loadings of 5, 10, 15, and $20 \mathrm{vol} \%$ as a function of temperature. The dielectric constant of pure epoxy remained practically constant, and it slightly increases from its value of 6.3 at $300 \mathrm{~K}$ above $320 \mathrm{~K}$. For both compositions, as the figure shows, the dielectric constant of the ferroelectric-epoxy thick films increases with increasing ceramics loading. All the samples exhibited a similar behaviour with temperature. At $300 \mathrm{~K}$ the dielectric constant values for $5,10,15$, and 20 vol\% loading were $8.3,11.3,13.3$, 17.7 , and $8.8,12.1,15,19.3$, respectively, for composites with BST(0.2) and BST(0.4) ceramics, at $10 \mathrm{KHz}$. Theses values remain lower than those of pure $\operatorname{BST}(0.2)$ and $\operatorname{BST}(0.4)$ ceramics (Figure 2).

For all the ceramic-epoxy composite samples, the dielectric constant increases slightly when the temperature rises. This increase becomes more significant when the temperature rises above $320^{\circ} \mathrm{K}$. The low dielectric constant value of both composites is due the low contents of the high-dielectric constant ceramic dispersed in the epoxy. In this case, the dielectric response mainly results from the continuous low dielectric constant epoxy matrix.

There are three competing mechanisms in the dielectric response of the ceramic-epoxy composites [19].

(1) The segmental mobility of polymer which increases with increasing temperature; this mechanism should increase the dielectric constant.

(2) The disruption of contacts between filler particles caused by the thermal expansion of resin and ceramic; this mechanism should decrease dielectric constant.

(3) The change in the dielectric response of the filler particles with temperature.

The dielectric constant of two composites ceramic polymer with the $20 \mathrm{vol} \%$ ceramics filler exhibits the highest increase as a function of temperature. In addition, the composite containing $\mathrm{BST}(0.4)$ has a higher dielectric constant than that based on BST(0.2). The former composite is therefore suitable for applications requiring moderately high dielectric constant. 


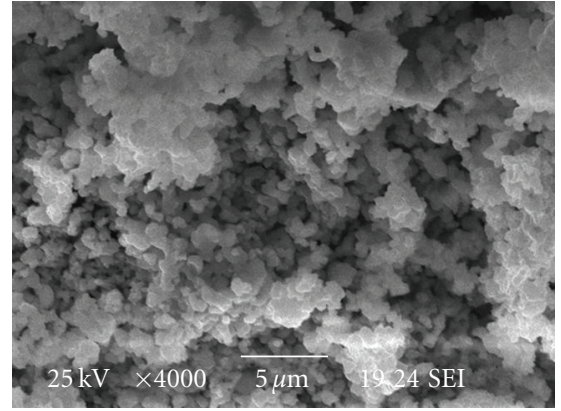

(a)

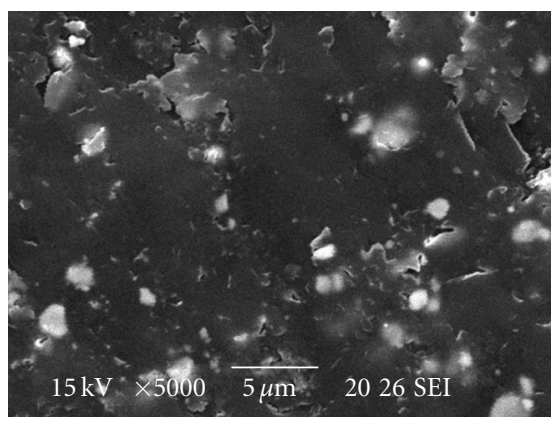

(c)

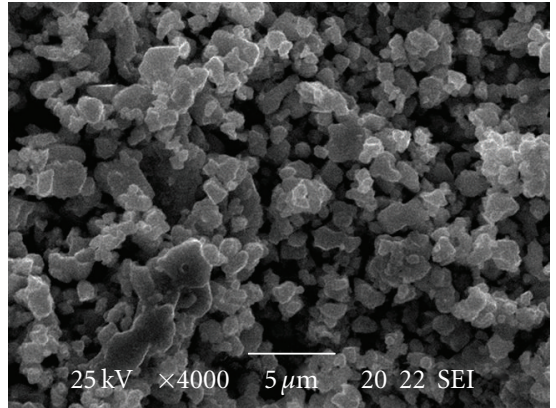

(b)

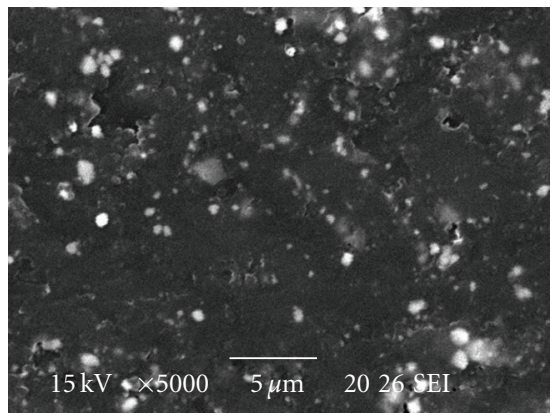

(d)

Figure 2: Micrographs of BST ceramic powders ((a) and (b)) and composites ((c) and (d)): (a) $x=0.2$, (b) $x=0.4$, (c) BST( $x=0.2)$-epoxy 10 vol $\%$, and (d) BST $(x=0.4)$-epoxy 15 vol $\%$.

Dielectric losses are low and vary between 0.026 and 0.033 for all the samples (Figure 5). For BST(0.4)-epoxy composites, the losses first increase when the volume fraction increases and then decrease with a maximum of 0.033 for $10 \mathrm{vol} \%$. A similar trend is exhibited by the composites based on BST(0.2)-epoxy for loading less than $10 \mathrm{vol} \%$. This behaviour is due to the fact that the dielectric properties of these composites are dominated by the main continuous phase of the polymer matrix at these loading rations [20]. According to the simple mixing rules, the dielectric losses are expected to increase monotonically with increasing filler ratio. In our case a maximum at $10 \%$ for $\operatorname{BST}(x=$ $0.4)$-epoxy and fluctuations in the case of the BST(0.2)epoxy were observed. This behaviour was also reported in other BST-polymer composites and was attributed to BST-epoxy interfacial phenomena that strongly influence the dielectric properties [21] of the composites. Further and detailed investigations of this peculiar behaviour are underway.

As shown in Figure 6, the dielectric constant of the composites decreases with increasing frequency. This behaviour can be attributed to a decrease in the dipolar polarisation in the matrix. Ramajo et al. [19] reported that this behaviour is more important at elevated temperature and low frequency for epoxy-barium titanate composite materials. In addition, owing to the heterogeneity of the composites, the contribution of the interfacial or Maxwell-WagnerSillars (MWS) polarisation [22] can also be responsible for this behaviour. In parallel, the displacement or orientation

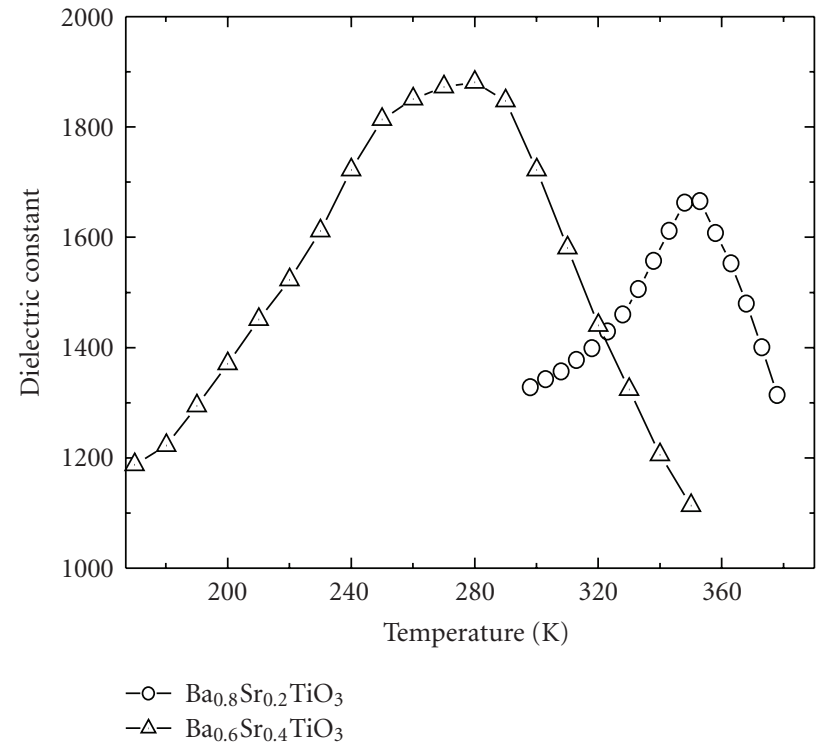

FIGURE 3: Temperature dependence of the dielectric constant of the sintered BST(0.2) and BST(0.4) ceramics.

of bound charge carriers responsible of other types of polarisations (atomic, electronic, dipolar) [23] may also play a role in this dispersion.

Different mixture laws were proposed to fit the experimental results such as the Series, Parallel, HashingShtrikman's, Looyenga, and Lichtenecker models. 


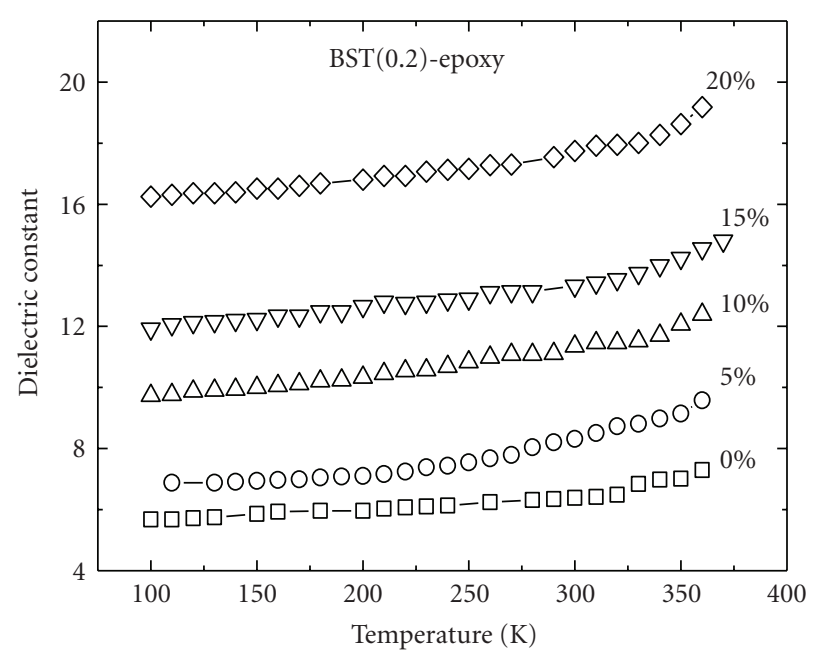

(a)

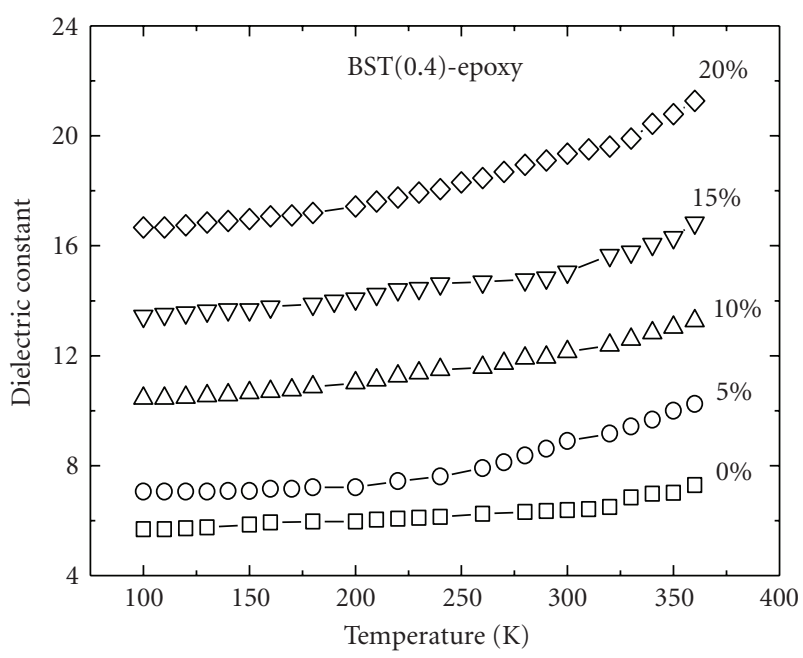

(b)

FIgURE 4: Dielectric constant for BST-epoxy composites as function of temperature for different volume fraction at $10 \mathrm{KHz}$.

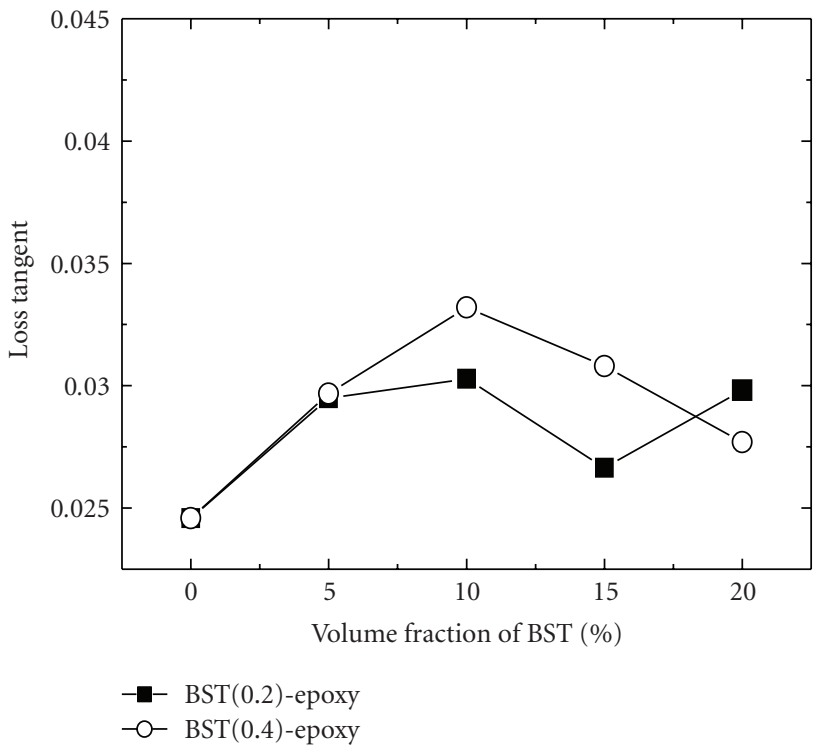

FIgURE 5: Loss tangent of BST-epoxy composites at $10 \mathrm{KHz}$ as function of volume fraction.

Figure 7 shows that the Lichtenecker model fits better the experimental results of both composites. In the case of BST(0.4) epoxy composite we notice a small deviation from the Lichtenecker model. This is probably due to the fact that this model assumes that the composite is a random mixture of spherical inclusions in the matrix [17]. The dielectric constant used in this formula is 6.3 for pure epoxy and 1246 and 1676 for sintered ceramics BST(0.2) and BST(0.4), respectively.

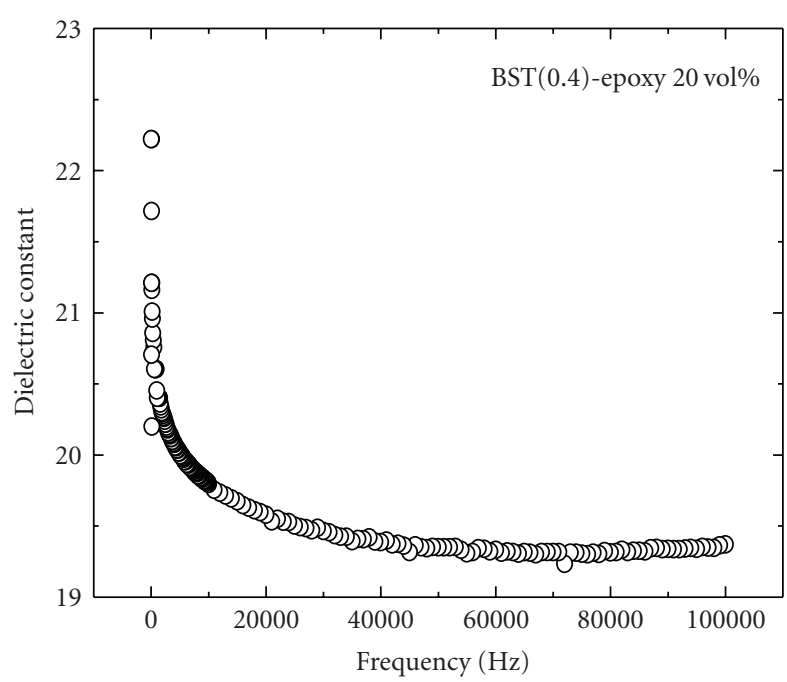

Figure 6: Dielectric constant of BST-epoxy sample with 20 vol\% loading as a function of frequency.

\section{Conclusion}

Composites BST-epoxy thick films were prepared by the knife-edge method from mixed ceramics powders and epoxy resin.

The dielectric constant of the composite thick films increased with increasing ceramic loading and slightly with temperature. The composite thick film with $20 \mathrm{vol} \%$ of BST(0.4) ceramic presented the highest dielectric constant. At these loading ratios the dielectric properties of these composites originate mainly from the contribution of the polymer matrix. 


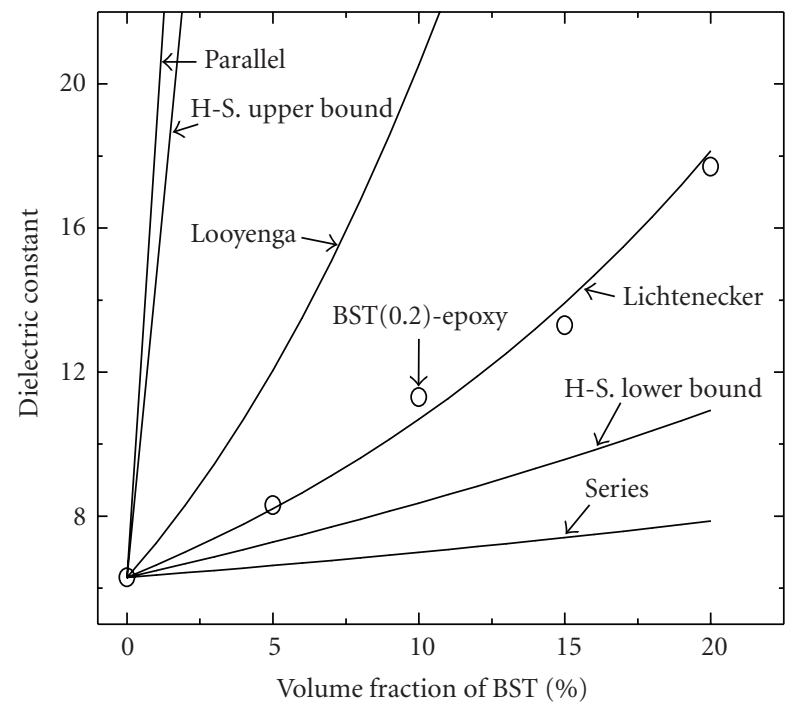

(a)

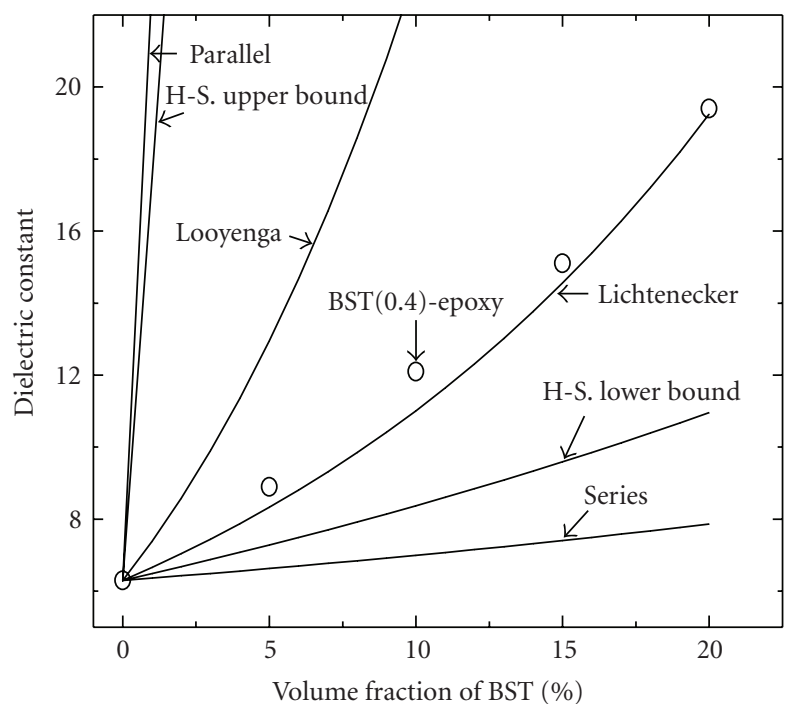

(b)

FIGURE 7: Theoretical mixture models and experimental result for BST-epoxy as function of volume fraction at $10 \mathrm{KHz}$.

The dielectric losses for both composite did not exceed 0.033. On the other hand, the dielectric constant decreases with increasing frequency. This dispersion may be caused by the Maxwell-Wagner-Sillars (MWS) polarisation, or by a displacement or orientation of bound charge carriers. Among dielectric mixing models, the Lichtenecker model accounts better for the experimental results for the both composites.

\section{References}

[1] T. Thongvigitmanee and G. S. May, "Modelling and optimization of integral capacitor fabrication using neutral networks," in Proceedings of the 26th IEEE/CPMT International Electronics Manufacturing Technology, pp. 300-303, Piscataway, NJ, USA, 2000.

[2] K. Uchino and S. Takahashi, "Dielectric ceramic materials," Ceramic Transactions, vol. 100, pp. 455-468, 1999.

[3] J. W. Liou and B. S. Chiou, "Dielectric tunability of barium strontium titanate/silicone-rubber composite," Journal of Physics Condensed Matter, vol. 10, no. 12, pp. 2773-2786, 1998.

[4] P. Chahal and R. R. Tummala, "A novel integrated decoupling capacitor for MCM-L technology," IEEE Transactions on Components Packaging and Manufacturing Technology B, vol. 21, no. 2, pp. 184-193, 1998.

[5] S. Bhattacharya, R. R. Tummala, P. Chahal, and G. White, "Integration of Polymer/Ceramic Thin Film Capacitors on PWB," in Proceedings of the International Symposium on Advanced Packaging Materials, pp. 68-70, 1997.

[6] C. Brosseau, F. Boulic, P. Queffelec, et al., "Dielectric and microstructure properties of polymer carbon black composites," Journal of Applied Physics, vol. 81, no. 2, pp. 882-891, 1997.

[7] M. A. Valente, L. C. Costa, S. Mendiratta, F. Henry, and L. Ramanitra, "Structural and electrical properties of polystyrene-carbon composites," Solid State Communications, vol. 112, no. 2, pp. 67-72, 1999.

[8] A. A. Khoroshilov, I. Koroleva, and Y. Bolodin, "Nickel/polystyrene composite electrode materials," Russian Journal of Applied Chemistry, vol. 73, no. 11, pp. 1918-1921, 2000.

[9] Y. Roichman, M. Silverstein, A. Siegmann, and M. Narkis, "Percolation of electrical conductivity in solution-cast blends containing polyaniline," Journal of Macromolecular Science: Physics, vol. B38, no. 1-2, pp. 145-161, 1999.

[10] K. Mazur, Ferroelectric Polymers: Chemistry, Physics and Applications, Marcel Dekker, New York, NY, USA, 1995.

[11] Y. Yan, L. Jin, L. Feng, and G. Cao, "Decrease of dielectric loss in giant dielectric constant $\mathrm{CaCu}_{3} \mathrm{Ti}_{4} \mathrm{O}_{12}$ ceramics by adding $\mathrm{CaTiO}_{3}, "$ Materials Science and Engineering B, vol. 130, no. 13, pp. 146-150, 2006.

[12] J. Kulek, I. Szafraniak, B. Hilczer, and M. Polomska, "Dielectric and pyroelectric response of PVDF loaded with $\mathrm{BaTiO}_{3}$ obtained by mechanosynthesis," Journal of Non-Crystalline Solids, vol. 353, no. 47-51, pp. 4448-4452, 2007.

[13] Y. Bai, Z. Y. Cheng, V. Bharti, H. S. Xu, and Q. M. Zhang, "High-dielectric-constant ceramic-powder polymer composites," Applied Physics Letters, vol. 76, no. 25, pp. 38043806, 2000.

[14] D. H. Kuo, C. C. Chang, T. Y. Su, W. K. Wang, and B. Y. Lin, "Dielectric properties of three ceramic/epoxy composites," Materials Chemistry and Physics, vol. 85, pp. 2001-2006, 2004.

[15] D. H. kuo, C. C. Lai, and T. Y. Su, "Dielectric behaviour of NbO5-doped $\mathrm{TiO}_{2}$ /epoxy thick films," Ceramic International, vol. 30, pp. 2177-2181, 2004.

[16] F. Amaral, C. P. L. Rubinger, F. Henry, L. C. Costa, M. A. Valente, and A. Barros-Timmons, "Dielectric properties of polystyrene-CCTO composite," Journal of Non-Crystalline Solids, vol. 354, no. 47-51, pp. 5321-5322, 2008.

[17] N. E. Frost, P. B. McGrath, and C. W. Burns, "Effect of fillers on the dielectric properties of polymers," in Proceedings of the 
IEEE International Symposium on Electrical Insulation, vol. 1, pp. 300-303, Montreal, Canada, 1996.

[18] D. H. Yoon, Z. Jianping, and I. Burtrand, "Dielectric constant and mixing model of $\mathrm{BaTiO}_{3}$ composite thick films," Materials Research Bulletin, vol. 38, no. 5, pp. 765-772, 2003.

[19] L. Ramjo, M. Robredo, and M. Castro, "Dielectric response and relaxation phenomena in composites of epoxy resin with $\mathrm{BaTiO}_{3}$ particles," Composites A, vol. 36, pp. 1267-1274, 2005.

[20] T. Hu, J. Juuti, H. Jantunen, and T. Vilkman, "Dielectric properties of BST/polymer composite," Journal of the European Ceramic Society, vol. 27, no. 13-15, pp. 3997-4001, 2007.

[21] M. Roy, J. K. Nelson, R. K. MacCrone, et al., "Polymer nanocomposite dielectrics-the role of the interface," IEEE Transactions on Dielectrics and Electrical Insulation, vol. 12, no. 4, pp. 629-642, 2005.

[22] G. Psarras, E. Manolakaki, and G. M. Tsangaris, "Electrical relaxations in polymeric particulate composites of epoxy resin and metal particles," Composites A, vol. 33, no. 3, pp. 375-384, 2002.

[23] G. M. Tsangaris, N. Kouloumbi, and S. Kyvelidis, "Interfacial relaxation phenomena in particulate composites of epoxy resin with copper or iron particles," Materials Chemistry and Physics, vol. 44, no. 3, pp. 245-250, 1996. 

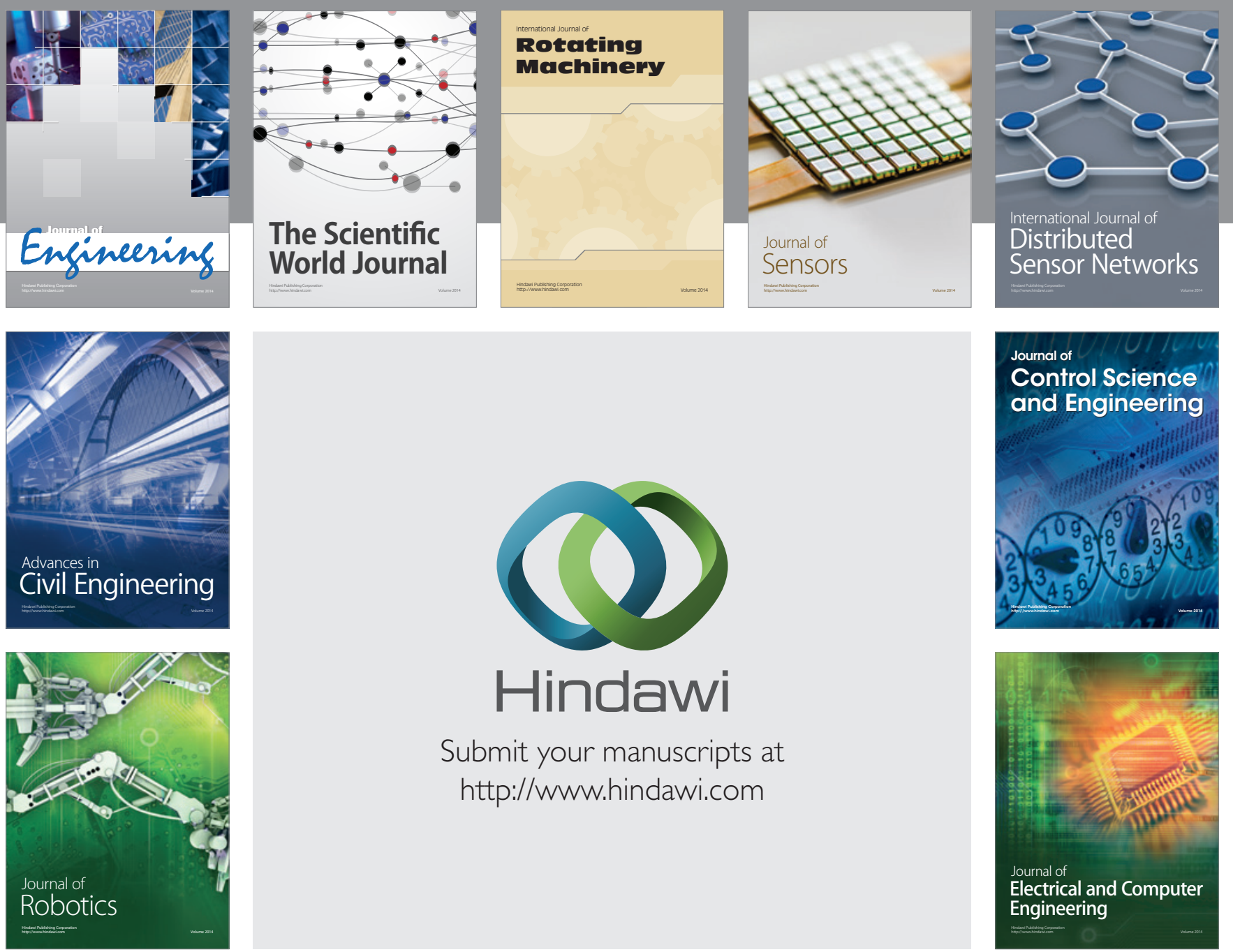

Submit your manuscripts at

http://www.hindawi.com
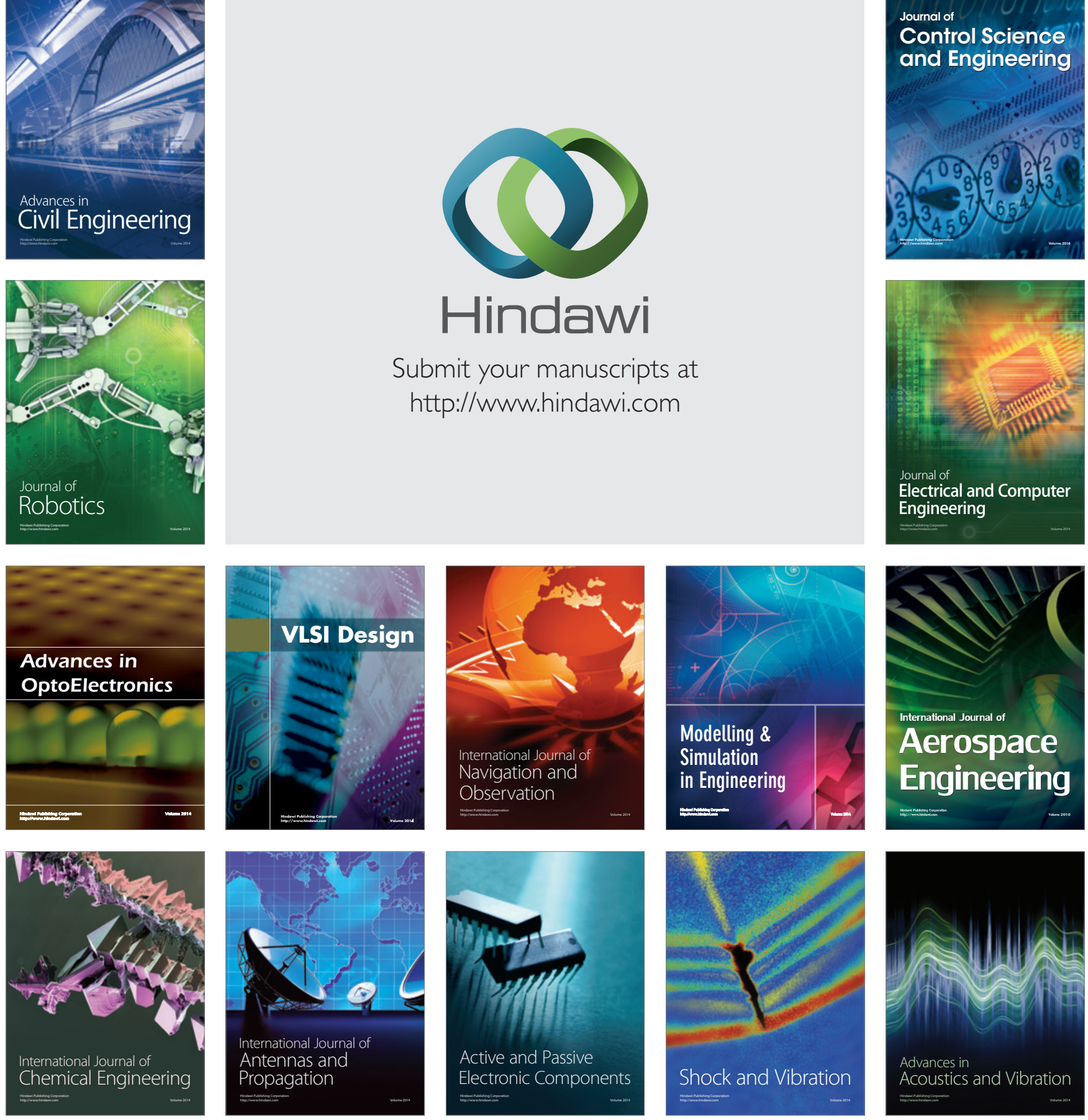